\title{
Structural and optical properties of synthesized poly(methyl methacrylate) (PMMA) and lanthanide $\beta$-diketonate complexes incorporated electrospun PMMA nanofibres for optical devices
}

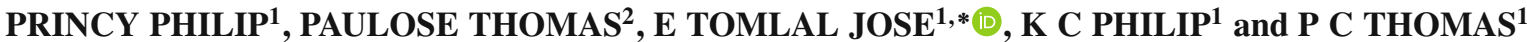 \\ ${ }^{1}$ Research and postgraduate, Department of Chemistry, St. Berchmans College, Changanacherry, Kottayam 686101 , India \\ ${ }^{2}$ Department of Physics, Marthoma College for Women, Perumbavoor 683542, India \\ *Author for correspondence (tomlalj27@gmail.com)
}

MS received 30 June 2018; accepted 3 March 2019

\begin{abstract}
Fabrication of electrospun nanofibres is the glittering area of research because of their flexible characteristics and numerous applications in almost all walks of life and technology. Poly(methyl methacrylate) (PMMA) is one of the significant and interested synthetic polymers in the recent research because of their characteristic properties like higher environmental stability, resistance to attack by moulds and enzymes, commercial availability, easiness to handle, etc. In the present study, pristine PMMA nanofibres with diameters of 60-150 nm with $109 \mathrm{~nm}$ as the most distributed one are prepared by an electrospinning method using a binary solvent mixture. An enhancement in the intensity of visible photoluminescence emission is observed in PMMA nanofibres embedded with samarium and neodymium $\beta$-diketonate complexes. The morphological incorporation of samarium and neodymium $\beta$-diketonate complexes in PMMA nanofibres and material composition of the samples are examined by high resolution electron microscopy analyses. The amorphous nature and molecular bonding of pure PMMA nanofibres and incorporated fibre complexes are elucidated through structural and molecular analyses. The supreme optical absorptions and reemissions of samarium and neodymium $\beta$-diketonate complexes embedded in the pure PMMA fibre sample in the visible region indicate not only their application in lighting or display devices, but also as active materials in organic light emitting diodes for new era curved/rolled display devices.
\end{abstract}

Keywords. Electrospinning; lanthanide $\beta$-diketonate PMMA nanofibre complexes; photoluminescence; PMMA nanofibre.

\section{Introduction}

Today, nanomaterials form a major part of research and analysis. Nanostructures like nanoparticles, nanowires, nanotubes, nanofibres, etc. are the topics of interest to the modern researchers since their applications are numerous. Among the various nanostructures, nanofibres have several characteristic properties like high surface area to volume ratio, flexibility in surface functionalities and superior mechanical properties like stiffness and tensile strength compared to other forms of the materials [1]. Polymer nanofibres act as good host matrices for nanoparticles, drugs, metals, etc. They have a wide variety of applications such as tissue engineering scaffolds, filtration membranes, dressings for wound healings, etc. [2] which enhanced the preparation of nanofibres through various methods like drawing, template synthesis, phase separation, self-assembly, electrospinning, etc. [1]. Among these methods, electrospinning is the most important and favourable one. It is the technique capable of producing polymer fibres in the nanometre diameter range from an electrostatically driven jet of polymer solution (or polymer melt). The different dimensions, shapes and porosity of polymer nanofibres can be obtained by varying the spinning parameters and polymer characteristics [3].

Herein, the present study progresses through three different stages. First is the preparation of electrospun poly(methyl methacrylate) (PMMA) nanofibres. PMMA is preferred since it is a commercially available synthetic polymer with exceptional characteristics like transparency, good tensile strength and processability as compared with other commercially available polymers. It is an economical alternative to other polymers such as polyacrylonitrile (PAN), polyvinylidene difluoride (PVDF), etc. [4]. The production of PMMA nanofibres with diameter $<100 \mathrm{~nm}$ is very much rare in the electrospinning field. The second stage of the study is the preparation of lanthanide $\beta$-diketonate complexes. Lanthanides like samarium and neodymium show excellent luminescence properties. $\beta$-Diketone ligands are preferred to prepare complexes because of their chemical stability, highly molar extinction coefficiency and high energy transfer efficiency from the ligand to the $\operatorname{Ln}(\mathrm{III})$ ions [5]. Lanthanide $\beta$-diketonate complexes are well-known molecular luminescent materials and they have characteristic emission bands [6]. Therefore, the incorporation of the luminescent material into 
the transparent matrix offers great advantages and hence the analyses on their optical properties are highly significant. The third stage of the study is the incorporation of these prepared lanthanide complexes into the prepared electrospun PMMA nanofibres and different analyses are carried out with special focus on the photoluminescence (PL) properties of pristine PMMA and PMMA nanofibres incorporated into the prepared samarium and neodymium complexes.

Today, numerous studies are being conducted for the preparation and characterization of electrospun polymer nanofibres and lanthanide complexes. For example, Lenaerts et al [6] prepared the lanthanide diketonate complexes with the theonyltrifluoroacetone (TTA) ligand by a precipitation method and immobilized these complexes into 1,10-phenanthroline functionalized merrifield resin and the luminescence characters were studied. Basak et al [7] worked on the PL properties of PMMA dispersed with silver nanoparticles and they observed a red shift when the polymer is dispersed with nanoparticles. Chahar et al [8] worked on PMMA nanofibres with neodymium oxide nanoparticles for lasers. They observed a shift in the PL spectrum with an increase in the concentration of lanthanide oxides. Most of the studies on PMMA electrospun polymer nanofibres are carried out either with silver nanoparticles or lanthanide oxides. Some of the researchers were found to prepare the lanthanide diketonate complexes but their further studies were quite different from that of us. Usually the particles, oxides or complexes are incorporated into nanofibres or any matrices after some surface treatments or with the assistance of ligands [6]; but here we are neither using any types of surface modification methods nor ligands; instead just using sonication, electrospinning and make advantage of the porous nature of electrospun nanofibres.

Usually the polymer nanofibres are prepared with single solvent like acetone or DMF or chloroform, etc. Herein, the present study, we have prepared PMMA electrospun polymer nanofibres with a binary solvent mixture, lanthanide diketonate complexes through the precipitation method and the PMMA nanofibres embedded with the prepared lanthanide ( $\mathrm{Sm}$ and $\mathrm{Nd}$ ) $\beta$-diketonate complexes and the various analyses are carried out to reach the goal of our study. In the present study, the comparative studies on the photoluminescent analysis of the PMMA nanofibres and PMMA nanofibres incorporated with the prepared lanthanide complexes show the characteristic properties and evidence for the ability of PMMA nanofibres to act as the best host matrices for lanthanide complexes with much enhancement in intensity. The present study is distinct from the other referred studies in the selection of the mentioned binary solvent mixture for the preparation of PMMA - which leads to the formation of better miscible solution of PMMA than using single solvent-and in the own preparation of lanthanide diketonate complexes and incorporation of the prepared lanthanide complex rather than the commercially available lanthanide complexes in our own prepared PMMA nanofibres and in the PL studies were further carried out. Studies on the incorporation of the as-such prepared complexes into PMMA electrospun nanofibres are not reported yet to the best of our knowledge. The present analysis proved that PMMA fibres could act as the best host matrix not only for pure lanthanides or lanthanide oxides but also for the lanthanide complexes with supreme optical properties. Accordingly, such type of lanthanide complexincorporated PMMA electrospun nanofibres can be used in various fields like lasers [8], light emitting diodes (LEDs) [9], chromatography, catalysts, sensors [10], waveguides, amplifiers, etc.

\section{Experimental}

\subsection{Materials}

The materials used in the present study are PMMA (molecular weight 15,000, Alfa Aesar), samarium chloride $\left(\mathrm{SmCl}_{3} \cdot 6 \mathrm{H}_{2} \mathrm{O}\right.$; Alfa Aesar; 99.9\%), sodium hydroxide ( $\mathrm{NaOH})$ (Merck), 2-TTA $\left(\mathrm{C}_{8} \mathrm{H}_{5} \mathrm{~F}_{3} \mathrm{O}_{2} \mathrm{~S}\right.$; Alfa Aesar; 99\%) and neodymium nitrate $\left(\mathrm{Nd}\left(\mathrm{NO}_{3}\right)_{3} \cdot 6 \mathrm{H}_{2} \mathrm{O}\right.$; Alfa Aesar; 99.9\%).

\subsection{Preparation of electrospun PMMA nanofibres}

The pristine PMMA nanofibres are synthesized through an electrospinning route. PMMA solution was prepared by dissolving $\sim 1 \%$ PMMA in a novel binary solvent mixture of chloroform and acetone in an equal ratio followed by mechanical stirring until a clear transparent solution of PMMA is obtained. It is then subjected to electrospinning and the parameters applied for the production of electrospun PMMA nanofibres are shown in table 1 . The electrospinning machine that we used for the production of PMMA nanofibres and the collected PMMA nanofibres are shown in figure 1a and $\mathrm{b}$.

\subsection{Synthesis of lanthanide(III) complexes}

The lanthanide $\beta$-diketonate complexes are prepared by precipitation method as described in the literature [6,11]. The solution is then subjected to centrifugation and washing with water. The precipitate obtained is then dried in a vacuum oven at $115^{\circ} \mathrm{C}$ for $6 \mathrm{~h}$. The samarium and neodymium $\beta$-diketonate complex powders prepared are shown in figure $2 \mathrm{a}$ and $\mathrm{b}$.

\section{3a Principle for the preparation of lanthanide complexes:}

$\beta$-Diketones exhibit keto-enol tautomerism. A total of $81 \%$ of the acetyl acetone molecules are present in the enol form at room temperature [9,12]. Keto-enol tautomerism in ligands like TTA is represented as $\mathrm{L}$ (keto) $\leftrightarrow \mathrm{L}$ (enol) or HL, where HL represents the enol form of the $\beta$-diketonate ligand. This

Table 1. Parameters of electrospinning.

\begin{tabular}{lcc}
\hline Voltage & Distance & Flow rate \\
\hline $20 \mathrm{kV}$ & $20 \mathrm{~cm}$ & $0.5 \mathrm{ml} \mathrm{h}^{-1}$ \\
\hline
\end{tabular}


(a)

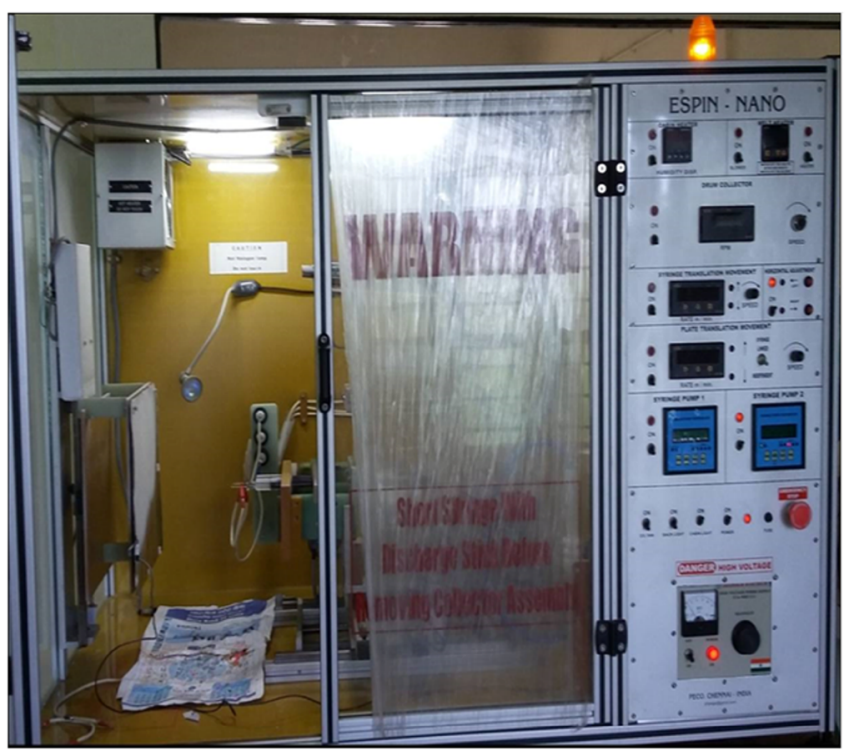

(b)

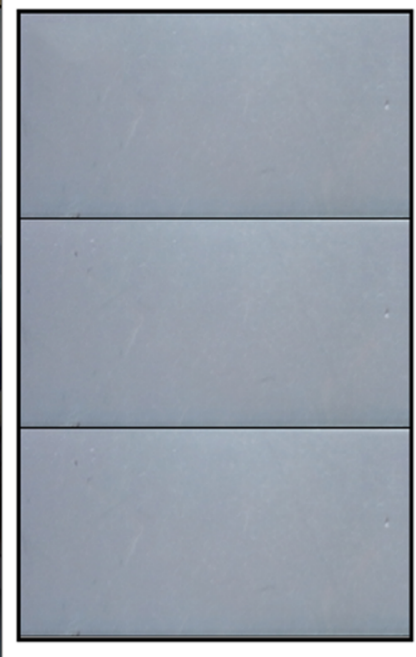

Figure 1. (a) Electrospinning machine and (b) electrospun PMMA nanofibres.
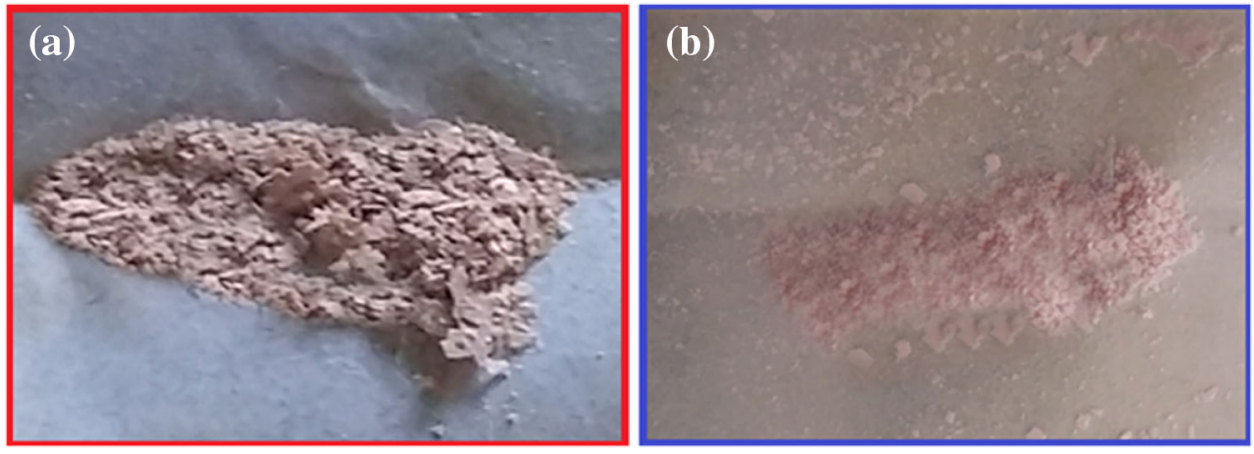

Figure 2. (a) Samarium $\beta$-diketonate complex and (b) neodymium $\beta$-diketonate complex.

$$
\text { keto form of TTA enol form of TTA }
$$

Scheme 1. Keto-enol tautomerism in diketonate ligands.

HL form of the $\beta$-diketonate ligand is believed to chelate with the metal ion as shown in scheme 1 .

Here ' $y$ ' represents the number of hydrated water molecules. The reaction of the enolic TTA to form the chelate with the metal ion is accompanied by the deprotonation of the ligand [11]. The common bases that are used for the deprotonation of $\beta$-diketones are ammonia, sodium hydroxide, piperidine or pyridine. When $\beta$-diketone is deprotonated, the proton is removed from the alcoholic group since $\beta$-diketone is in the enol form. The addition of ethanol enhances the complexation due to an increase in dissolution and tautomerization of TTA to the 'enol' form from the 'keto' form [9]. The formed chelate includes water molecules, i.e., the chelate will be in the form of $\mathrm{Sm}(\mathrm{TTA})_{3} \cdot\left(\mathrm{H}_{2} \mathrm{O}\right)_{2}$ and $\mathrm{Nd}(\mathrm{TTA})_{3} \cdot\left(\mathrm{H}_{2} \mathrm{O}\right)_{3}$. This means that the samarium complex formed by chelation with TTA is found to be dihydrate and the neodymium complex is found to be trihydrate [6].

\subsection{PMMA electrospun nanofibres embedded with the samarium (+3) and neodymium (+3) $\beta$-diketonate complex}

The prepared $\mathrm{Sm}(\mathrm{III})$ and $\mathrm{Nd}(\mathrm{III}) \beta$-diketonate complex is dispersed in 1\% PMMA solution and subjected to sonication [9]. It is then electrospun with an applied voltage of $20 \mathrm{kV}$ at a flow rate of $0.5 \mathrm{ml} \mathrm{h}^{-1}$ with a collector distance of $20 \mathrm{~cm}$ and the fibres are collected in 
(a)

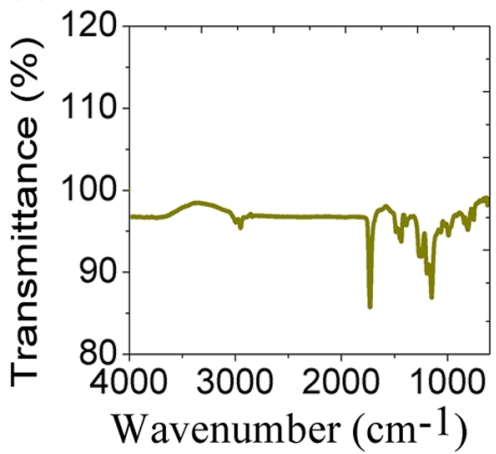

(b)

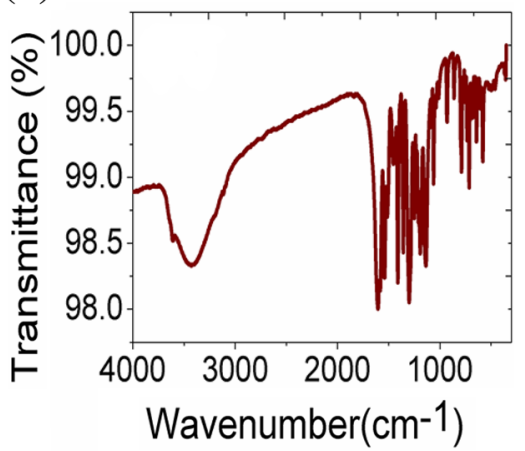

(c)

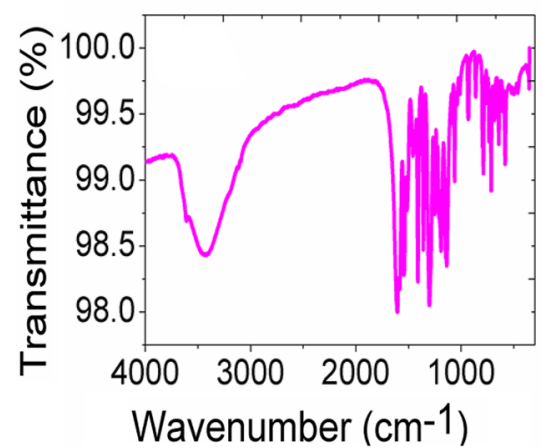

(d)

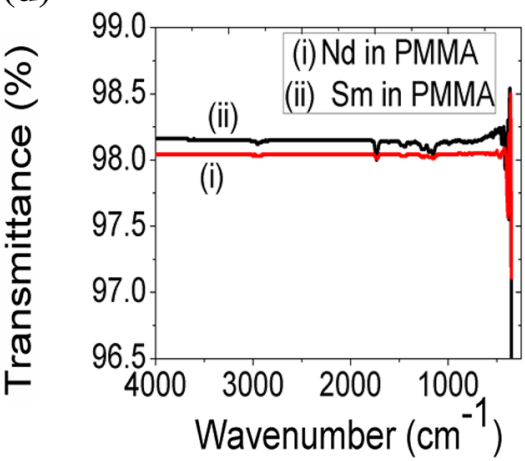

Figure 3. FTIR spectra: (a) pure PMMA nanofibres, (b) Sm complex, (c) Nd complex and (d) (i) PMMA nanofibres incorporated with the Sm complex and (ii) PMMA nanofibres incorporated with the $\mathrm{Nd}$ complex.

an aluminium foil. The obtained pure PMMA nanofibres, Sm(III) $\beta$-diketonate complex, $\mathrm{Nd}$ (III) $\beta$-diketonate complex, PMMA electrospun nanofibres embedded with the Sm(III) $\beta$-diketonate complex and $\mathrm{Nd}(\mathrm{III}) \quad \beta$-diketonate complex were subjected to various analytical techniques like scanning electron microscopy (SEM), energy dispersive X-ray spectroscopy (EDX), Fourier transformed infrared (FTIR), ultraviolet (UV), PL, etc.

\subsection{Measurements}

FTIR analyses of the samples were carried out using an instrument PerkinElmer spectrum two, XRD analyses of the samples were carried out using a Rigaku MiniFlex 600 X-ray diffractometer, UV-visible absorption analyses are carried out with a T90+ spectrometer from PG instruments, SEM analyses of the samples are carried out with a JEOL Model-JSM 6390LV, field emission scanning electron microscopy (FESEM) analysis of the PMMA nanofibres is carried out using a Nova NanoSEM 450 UoK, transmission electron microscopy (TEM) and EDX analyses of the samples were performed with a high-resolution transmission electron microscope facility, JEM 2100 and PL studies were conducted using PerkinElmer LS45.

\section{Results and discussion}

\subsection{FTIR analysis}

The FTIR spectra of the pure PMMA, samarium $\beta$-diketonate complex, neodymium $\beta$-diketonate complex, electrospun PMMA nanofibres embedded with the samarium and neodymium $\beta$-diketonate complexes and the assignment of peaks in each case are shown in figure $3 \mathrm{a}-\mathrm{d}$ and table 2 , respectively.

The characteristic peaks of PMMA are obtained at $2951 \mathrm{~cm}^{-1}$ which is assigned to the $\mathrm{C}-\mathrm{H}$ stretching band of PMMA and at $1734 \mathrm{~cm}^{-1}$ which is due to the vibration of the $\mathrm{C}=\mathrm{O}$ group in PMMA [13-16]. The obtained FTIR spectra in the case of the samarium and neodymium $\beta$-diketonate complex clearly give evidence for the successful production of these complexes with the TTA ligand. The broad band appeared in the range of $3734-3078 \mathrm{~cm}^{-1}$ is highly notable as it clearly proves the presence of the $\mathrm{OH}$ group in the sample. The absence of the peak at $3109 \mathrm{~cm}^{-1}$, which is characteristic of the $\mathrm{CH}_{2}$ stretching of TTA spectra of the complex, also proves the presence of the complex in the enol form [17].

Most of the previous literature studies specify two strong bands in the range of $1500-1650 \mathrm{~cm}^{-1}$ in which the bands with higher frequency is associated with the chelated 
Table 2. FTIR assignments.

\begin{tabular}{|c|c|c|c|}
\hline Sl. no. & Sample & Wavenumber $\left(\mathrm{cm}^{-1}\right)$ & Assignments \\
\hline \multirow[t]{7}{*}{1} & \multirow[t]{7}{*}{ Pure PMMA } & 2951 & PMMA C-H stretching band \\
\hline & & 1734 & PMMA C=O band \\
\hline & & 1440 & $\mathrm{H}-\mathrm{C}-\mathrm{H}$ bend in PMMA \\
\hline & & 1144 & $\mathrm{C}-\mathrm{O}-\mathrm{C}$ of the methoxy group of PMMA \\
\hline & & 985 & $\mathrm{C}-\mathrm{C}$ stretching PMMA \\
\hline & & 803 & $\mathrm{C}=\mathrm{O}$ in plane bending \\
\hline & & 746 & $\mathrm{C}=\mathrm{O}$ out of plane bending \\
\hline \multirow[t]{7}{*}{2} & \multirow[t]{7}{*}{ Samarium complex } & 3734-3078 & $\mathrm{OH}$ group present in the sample \\
\hline & & 1614 & Chelated $\mathrm{C}=\mathrm{O}$ group \\
\hline & & 1539 & $\mathrm{C}=\mathrm{C}$ in the complex \\
\hline & & 1400 & Double bonds in thiophene ring \\
\hline & & 1300 & C-F stretching vibration of TTA \\
\hline & & 1109 & $\mathrm{C}-\mathrm{S}$ stretching vibration of TTA \\
\hline & & 528 & Stretching vibration of $\mathrm{Sm}_{2} \mathrm{O}_{3}$ molecules \\
\hline \multirow[t]{7}{*}{3} & \multirow[t]{7}{*}{ Neodymium complex } & $3734-3078$ & $\mathrm{OH}$ group present in the sample \\
\hline & & 1614 & Chelated $\mathrm{C}=\mathrm{O}$ group \\
\hline & & 1539 & $\mathrm{C}=\mathrm{C}$ in the complex \\
\hline & & 1400 & Double bonds in the thiophene ring \\
\hline & & 1300 & $\mathrm{C}-\mathrm{F}$ stretching vibration of TTA \\
\hline & & 1109 & C-S stretching vibration of TTA \\
\hline & & $548-560$ & Stretching vibration of $\mathrm{Nd}_{2} \mathrm{O}_{3}$ molecules \\
\hline \multirow[t]{5}{*}{4} & \multirow{5}{*}{$\begin{array}{l}\text { PMMA nanofibres incorporated } \\
\text { with samarium complex }\end{array}$} & 2954 & PMMA C-H stretching band \\
\hline & & 1738 & PMMA C $=\mathrm{O}$ band \\
\hline & & 1442 & $\mathrm{H}-\mathrm{C}-\mathrm{H}$ bend in PMMA \\
\hline & & 1400 & Double bonds in thiophene ring \\
\hline & & $1226-1300$ & C-F stretching vibration of TTA \\
\hline \multirow[t]{4}{*}{5} & \multirow{4}{*}{$\begin{array}{l}\text { PMMA nanofibres incorporated } \\
\text { with neodymium complex }\end{array}$} & $2954-2935$ & PMMA C-H stretching band \\
\hline & & 1740 & PMMA C $=\mathrm{O}$ band \\
\hline & & $1428-1489$ & Double bonds in thiophene ring \\
\hline & & 1300 & C-F stretching vibration of TTA \\
\hline
\end{tabular}

carbonyl group, while the other with lower frequency is associated with the carbon-carbon double bond present in the complex. However, some literature studies narrate only one band which assigns to the carbon-carbon double bond in the complex [18]. Two peaks are obtained at 1614 and $1539 \mathrm{~cm}^{-1}$ which are characteristic of the chelated $\mathrm{C}=\mathrm{O}$ group and $\mathrm{C}=\mathrm{C}$ group, respectively. The spectrum also shows the existence of the thiophene ring in the complex with a peak at $1400 \mathrm{~cm}^{-1}$ which is a strong evidence for the successful production of the complexes with the TTA ligand.

The peak at $528 \mathrm{~cm}^{-1}$ shows the presence of $\mathrm{Sm}_{2} \mathrm{O}_{3}$ molecules present in the sample [19] and the peak at $548-560 \mathrm{~cm}^{-1}$ shows the presence of $\mathrm{Nd}_{2} \mathrm{O}_{3}$ molecules present in the sample [20,21]. The observed peak at $2954 \mathrm{~cm}^{-1}$ in PMMA nanofibres embedded with the samarium $\beta$ diketonate complex and that at $2954-2935 \mathrm{~cm}^{-1}$ in PMMA nanofibres embedded with the neodymium $\beta$-diketonate complex correspond to the stretching band of PMMA. The peak obtained at $1738 \mathrm{~cm}^{-1}$ in PMMA nanofibres embedded with the samarium $\beta$-diketonate complex and that at $1740 \mathrm{~cm}^{-1}$ in PMMA nanofibres embedded with the neodymium $\beta$ diketonate complex also highlights the presence of PMMA with the vibration of the $\mathrm{C}=\mathrm{O}$ group. Both these peaks show a blue shift of $3-4 \mathrm{~cm}^{-1}$ from their corresponding peaks in pure PMMA which indicates the replacement of coordinated water molecules with carbonyl groups from PMMA. This also indicates that the interaction between $\mathrm{C}=\mathrm{O}$ groups of PMMA and lanthanide ions are formed by doping besides the Van der Waals contacts and electrostatic forces [22].

The broad peak obtained in the range $3734-3408 \mathrm{~cm}^{-1}$ totally disappears in the spectra of PMMA embedded with lanthanide complexes which is a clear evidence of the absence of the $\mathrm{OH}$ group due to the complete evaporation of ethanol and water molecules in the complex during the process and it also agrees to a strong interaction between the complex and the PMMA fibres in electrospinning. The sharp peaks obtained at 1400 and $1300 \mathrm{~cm}^{-1}$ correspond to the vibrations of double bonds in the thiophene ring and the $\mathrm{C}-\mathrm{F}$ stretching of TTA in the complexes, respectively. These peaks become broadened when the complex is incorporated into the host PMMA matrix which supports the notable interaction between PMMA and the complex on electrospinning. The spectra of electrospun PMMA nanofibres embedded with samarium and neodymium $\beta$-diketonate complexes contain 
(a)

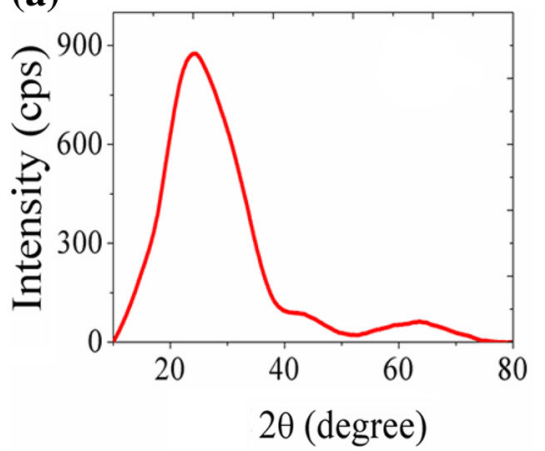

(b)

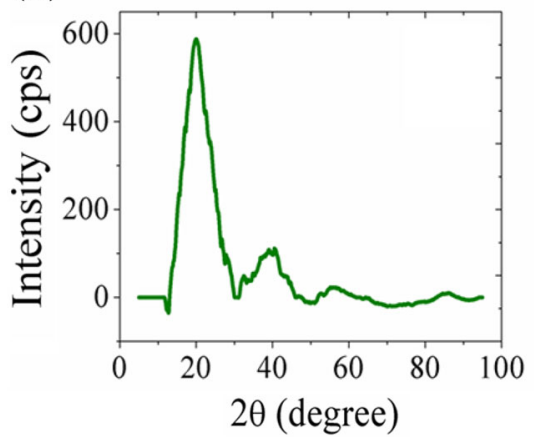

(c)

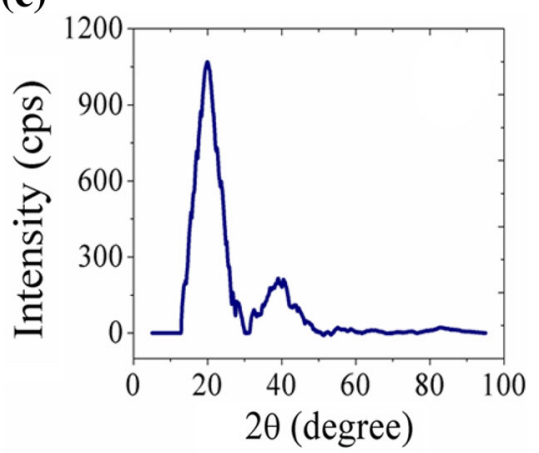

(d)

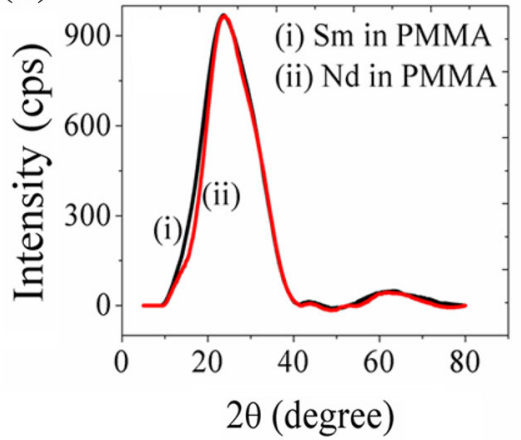

Figure 4. XRD spectra: (a) pure PMMA nanofibres, (b) Sm complex, (c) Nd complex and (d) (i) PMMA nanofibres incorporated with the Sm complex and (ii) PMMA nanofibres incorporated with the Nd complex.

the characteristic peaks of both pure PMMA electrospun nanofibres and samarium and neodymium $\beta$-diketonate complexes. It is also observed that the peaks are shifted to higher wavenumbers on incorporating the complexes into PMMA.

\subsection{XRD analysis}

The XRD pattern of the pure PMMA, samarium $\beta$-diketonate complex, neodymium $\beta$-diketonate complex and electrospun PMMA nanofibres embedded with the samarium and neodymium $\beta$-diketonate complexes are shown in figure $4 \mathrm{a}-\mathrm{d}$.

The peaks at $24.2,43.3$ and $63.1^{\circ}$ observed in figure $4 \mathrm{a}$ correspond to PMMA and they match well with the data available in the literature [7]. The XRD patterns of the prepared complexes shown in figure $4 \mathrm{~b}$ and $\mathrm{c}$ are compared with the standard results available in MATCH! 2 software and found that the obtained XRD patterns are in good agreement with samarium oxide and neodymium oxide. The broadened peaks observed at 20 and $39^{\circ}$ in the complex samples indicate their amorphous nature $[23,24]$. The XRD pattern obtained for the sample containing the samarium and neodymium complexes incorporated into PMMA nanofibre (figure 4d) is the same as that observed for pure PMMA. It does not show separate peaks of PMMA but the complexes show that the particles are well incorporated into the PMMA nanofibres. It is also observed that on incorporating the complexes into PMMA nanofibres the values show a slight shift to lower angles than in pure PMMA. This is due to the interaction between the fibres and complexes.

\subsection{UV-visible absorption analysis}

The UV-visible spectra of the pure PMMA, samarium $\beta$ diketonate complex and neodymium $\beta$-diketonate complex, PMMA nanofibres embedded with the samarium and neodymium $\beta$-diketonate complexes are shown in figure 5a-d.

It is evident from figure 5a that PMMA has absorption in the visible region. The UV-visible spectra of samarium and neodymium $\beta$-diketonate complexes shown in figure $5 \mathrm{~b}$ are in close agreement with the previous reports [25]. The prepared samarium and neodymium complexes show strong absorption in the UV-visible region. Two main absorption peaks observed at 266 and $340 \mathrm{~nm}$ denote the $\pi-\pi^{*}$ transitions of the thiophene ring and the carbonyl group present in the TTA ligand [18]. This indicates the formation of the complexes. The UV-visible spectra of PMMA electrospun nanofibres embedded with the samarium and neodymium $\beta$-diketonate complexes shown in figure $5 \mathrm{c}$ and $\mathrm{d}$ exhibit a significant difference from those of samarium and neodymium complexes.

When the complex is inserted into the host PMMA polymer matrix the absorption observed at $266 \mathrm{~nm}$ of the complex 

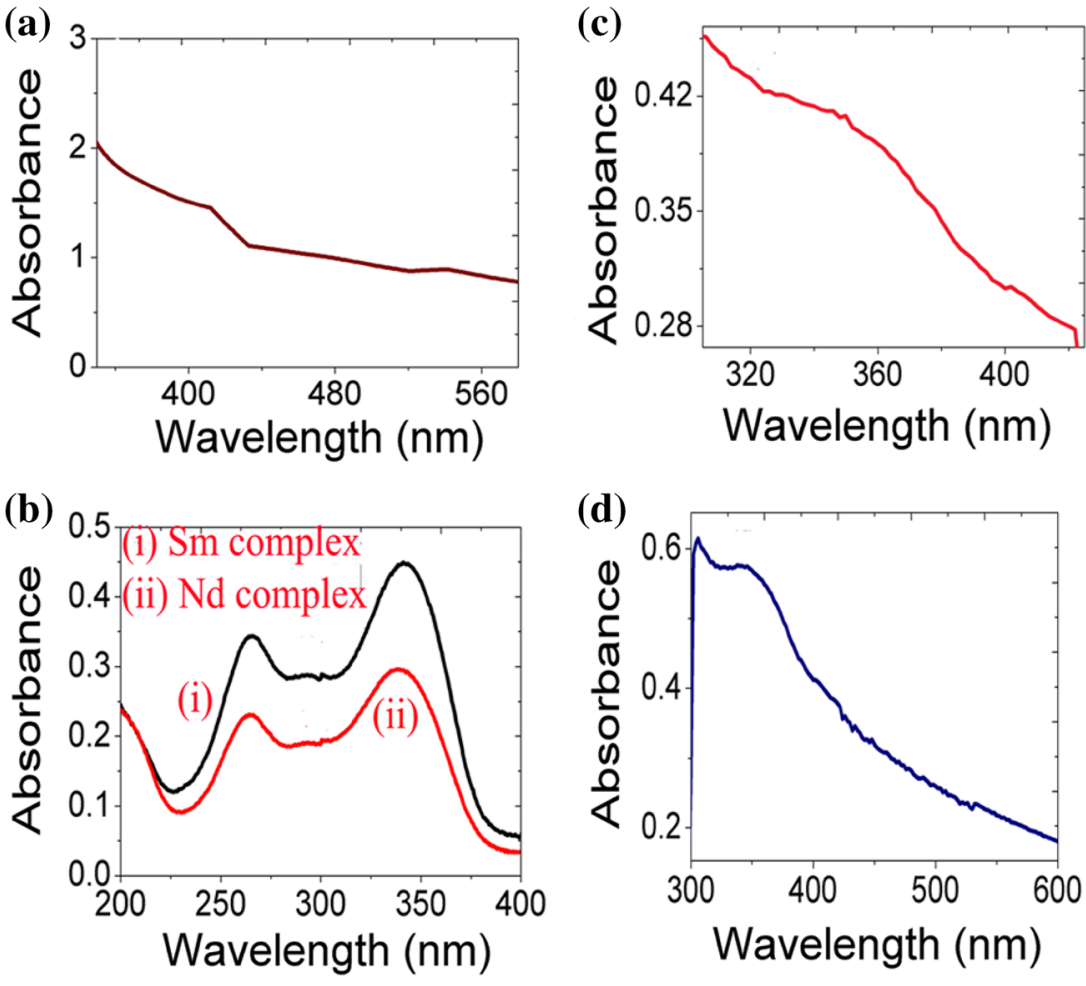

Figure 5. UV-visible absorption spectra: (a) pure PMMA nanofibres, (b) (i) Sm complex and (ii) Nd complex, (c) PMMA nanofibres incorporated with the Sm complex and (d) PMMA nanofibres incorporated with the Nd complex.

is shifted to $278 \mathrm{~nm}$ in the case of PMMA incorporated with samarium and to $281 \mathrm{~nm}$ in the case of PMMA nanofibres incorporated with neodymium and the band obtained at $340 \mathrm{~nm}$ is broadened to $390 \mathrm{~nm}$ in both cases. This is because of the interactions between the complex and the polymer fibre and this again confirms the successful incorporation of the complex into the polymer matrix.

\subsection{SEM analysis}

The SEM analysis results of the pure PMMA, samarium $\beta$-diketonate complex, neodymium $\beta$-diketonate complex, PMMA nanofibres embedded with the samarium and the neodymium $\beta$-diketonate complex are shown in figure 6a-e.

The SEM image of pure PMMA electrospun nanofibres shows the uniform production of nanofibres without any beads or deformations. The diameters of the fibres are determined using WCIF image $\mathrm{J}$ software and it is found to be in the range of $60-150 \mathrm{~nm}$ with $109 \mathrm{~nm}$ as the most distributed fibre. The pristine PMMA nanofibres with a diameter below $100 \mathrm{~nm}$ by using only $1 \%$ PMMA solution are a new milestone in the polymer field.

The SEM analysis of samarium and neodymium $\beta$-diketonate complexes shows that the obtained morphologies are not uniform and it does not show any predicted surface morphology. It is observable from figure $6 \mathrm{~b}$ and $\mathrm{c}$ that the complexes have a variety of shapes like square, rectangular, pentagonal, hexagonal, etc. The luminous nature of the complexes is also visible in the SEM images of these complexes. The agglomerated nature of the complex elucidated the formation of a precipitate when the solution is cooled from $60^{\circ} \mathrm{C}$ to room temperature. The SEM images of lanthanide complexes incorporated PMMA do not contain any beads which indicates the appropriate combination and the intended interaction between the complexes and the host PMMA polymer matrix. The luminous nature of PMMA nanofibres, as observable from figure $6 \mathrm{~d}$ and $\mathrm{e}$, indicates the successful incorporation of a luminescent complex with the transparent PMMA polymer matrix. Figure $7 \mathrm{~b}$ and $\mathrm{c}$ shows that the diameter of PMMA nanofibres is increased to a certain extent after incorporating the complexes into them which again shows the successful incorporation of the complexes into PMMA nanofibres.

Some broken structures which look like flakes are observed in the electrospun PMMA nanofibres incorporated with samarium and neodymium complexes as shown in figure $6 \mathrm{~d}$ and e. These flake structures are originated by the microexplosions on the nanofibres due to the high electric field used in electrospinning. Some of the regions of the nanofibres are unstable and hence it has a possibility to break these regions by high pressure during the incorporation of lanthanide complexes into fibres. The flake-like regions are part of fibres and not separated from fibres. Thus, it is confirmed that the broken regions are not originated by any chemical reaction between the fibres and complexes. 

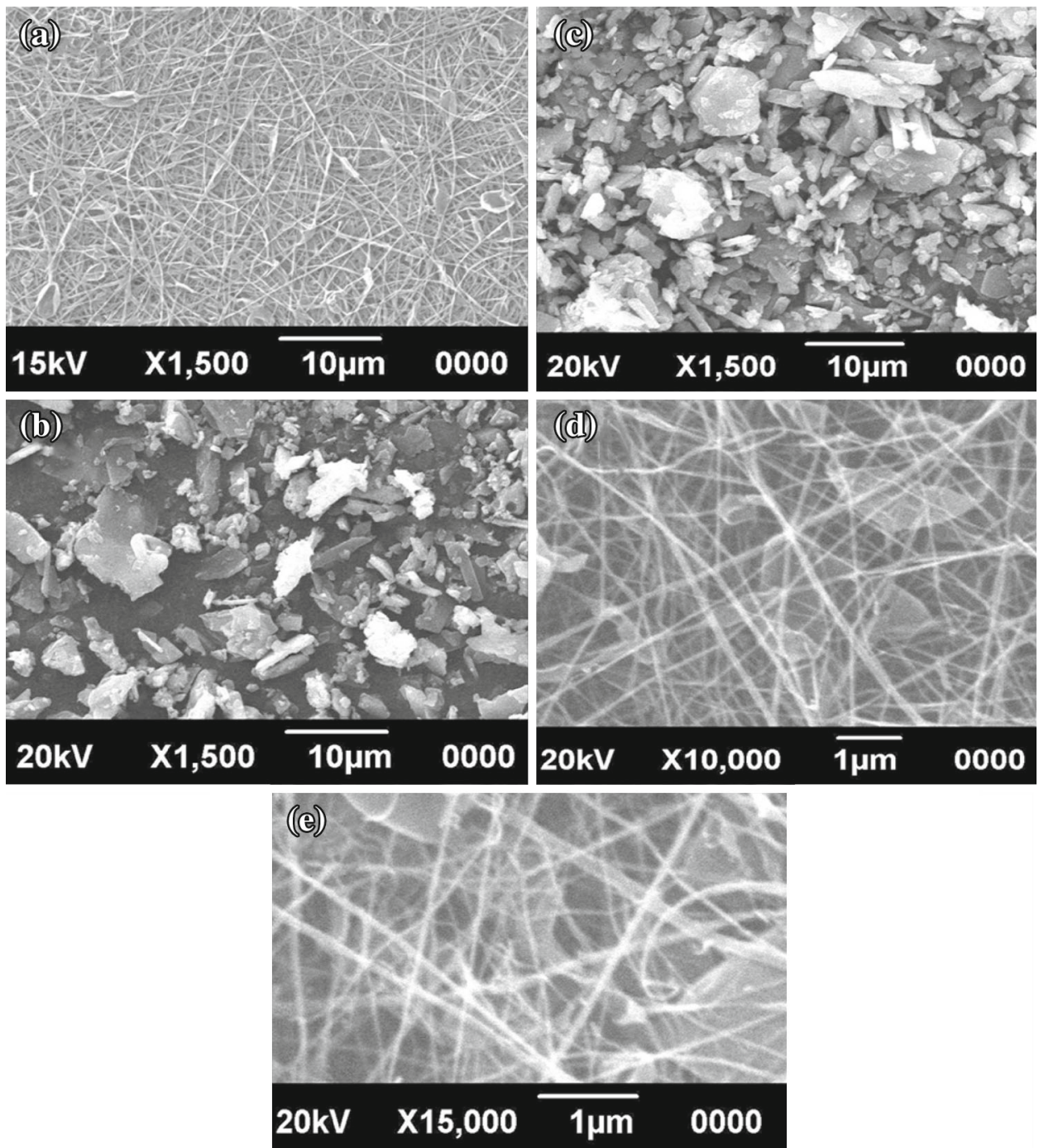

Figure 6. SEM images: (a) pure PMMA nanofibres, (b) Sm complex, (c) Nd complex, (d) PMMA nanofibres incorporated with the Sm complex and (e) PMMA nanofibres incorporated with the Nd complex.

The incorporation of particles into the nanofibre is also well established by TEM images. The complex particles can be incorporated into nanofibres as the fibre surface is porous due to the evaporation of solvents besides the physical interaction between PMMA and complexes. The particles can spread everywhere in a non-uniform pattern since particles are nonuniform in size and shape; but it is clear from SEM images that the number of flakes is much less than the number of fibres which show that the properties of fibres incorporated with particles will be influenced by particles alone than flakes. These flakes still exist as parts of fibres only. We cannot say that the particles are inside or on the surface of the fibre since the fibre is too thin to measure on the inside and the outer surface and also since it is not in the coaxial hollow form. The particles can be trapped into the hollow space inside the fibre if the fibre is in the coaxial hollow form only. But here it is not like that.
The fibre diameter distribution of pure PMMA and PMMA nanofibres embedded with samarium and neodymium $\beta$ diketonate complexes is shown in figure $7 \mathrm{a}-\mathrm{c}$ and the surface plot image of pure PMMA and PMMA nanofibres embedded with the samarium and neodymium $\beta$-diketonate complexes are shown in figure $7 \mathrm{~d}-\mathrm{f}$.

The surface plot images, a tool available in WCIF Image $\mathrm{J}$ software, shown in figure $7 \mathrm{~d}-\mathrm{f}$ also proves the fibre diameter distribution. Here $X$ and $Y$ axes represent the length and breadth of the selected area of the image under consideration and the $Z$ axis represents the diameters of the fibres in the selected area as height. We can see from figure $7 \mathrm{~d}$ that the diameter of the produced PMMA fibres are in the range of $60-150 \mathrm{~nm}$ with $109 \mathrm{~nm}$ as the most distributed one. It also shows the presence of ultrafine PMMA nanofibres with a diameter below $100 \mathrm{~nm}$. Figure $7 \mathrm{e}$ and $\mathrm{f}$ shows that there is an increase in the fibre diameter after incorporation of 

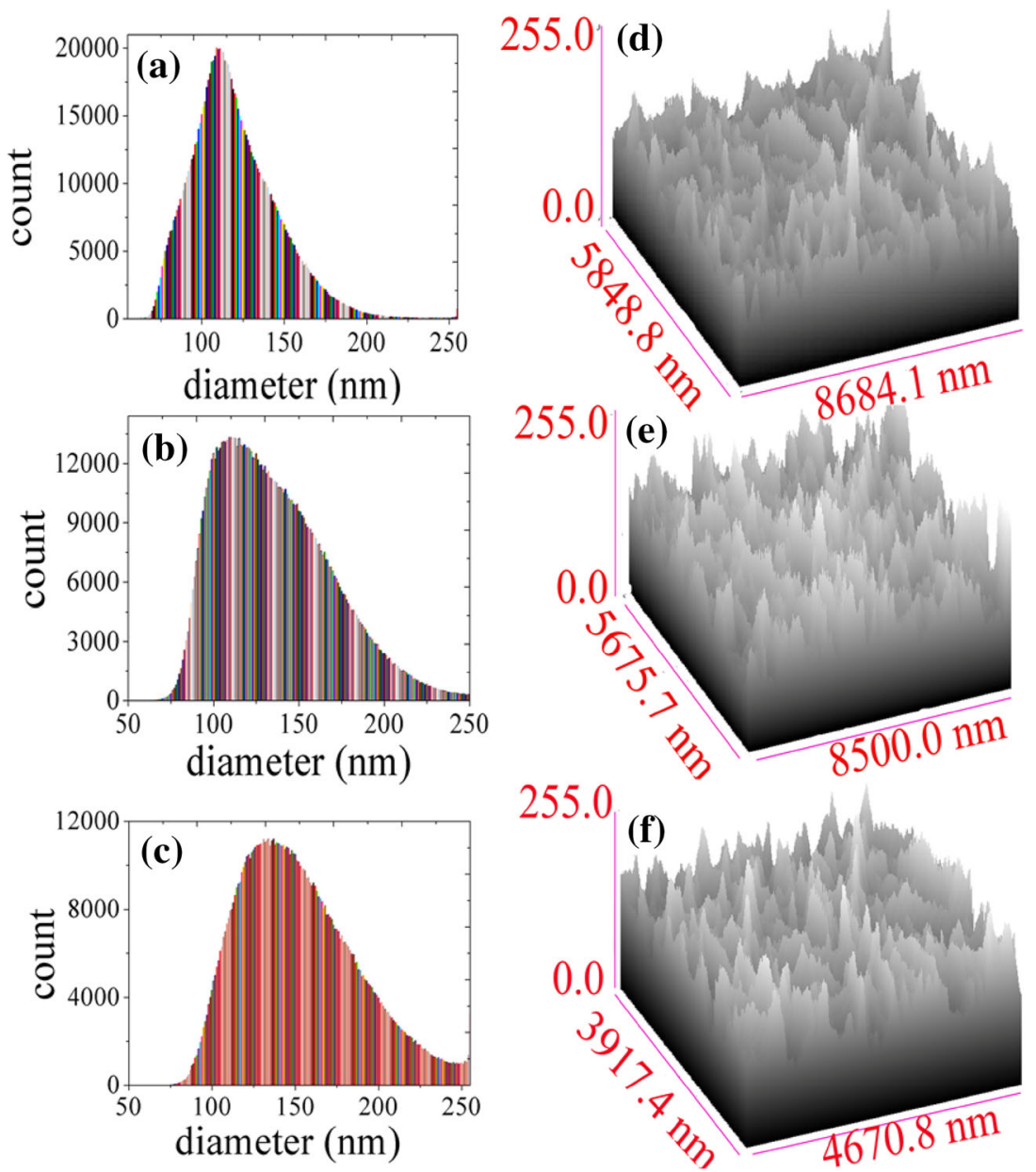

Figure 7. (a) Histogram of PMMA nanofibres, (b) histogram of PMMA nanofibres incorporated with the Sm complex, (c) histogram of PMMA nanofibres incorporated with the Nd complex, (d) surface plot of PMMA nanofibres, (e) surface plot of PMMA nanofibres incorporated with the Sm complex and (f) surface plot of PMMA nanofibres incorporated with the $\mathrm{Nd}$ complex.

the complexes into PMMA. There is a little variation among the individual fibre diameters in the case of PMMA nanofibres embedded with the samarium $\beta$-diketonate complex but these types of variations are not oftentimes present in the case of PMMA nanofibres embedded with the neodymium $\beta$ diketonate complex. Histograms of these samples also prove this point. All these factors give clear cut evidence for the successful incorporation of the lanthanide complexes in the PMMA nanofibre.

\subsection{FESEM analysis}

FESEM analysis of the PMMA nanofibres is carried out to understand the surface properties and characteristics of the prepared nanofibres in very high resolution and is shown in figure 8 . The result shows the production of smooth electrospun PMMA nanofibres without any beads or deformations. The inset of figure 8 shows the close up view of the porous surface of electrospun PMMA nanofibres. All the electrospun fibres are porous to an extent due to the evaporation of solvents during the electrospinning process itself. The porous nature of electrospun PMMA fibres helps to hold thoroughly the complex incorporated into it which supports the results of XRD. The porous surface can hold those complex particles which are suitable to its size and shape. The enhanced intensity observed in PL spectra of these samples also shows that sufficient number of particles is present in the fibre. The porous surface also proves the heterogeneous nature of the fibre surface which is helpful for further investigations that are progressing very well.

\subsection{TEM analysis}

TEM analysis of the PMMA electrospun nanofibres embedded with samarium and neodymium $\beta$-diketonate complexes are shown in figure $9 a$ and $b$, respectively. The TEM images of the PMMA electrospun nanofibres embedded with samarium and neodymium $\beta$-diketonate complexes show the successful 


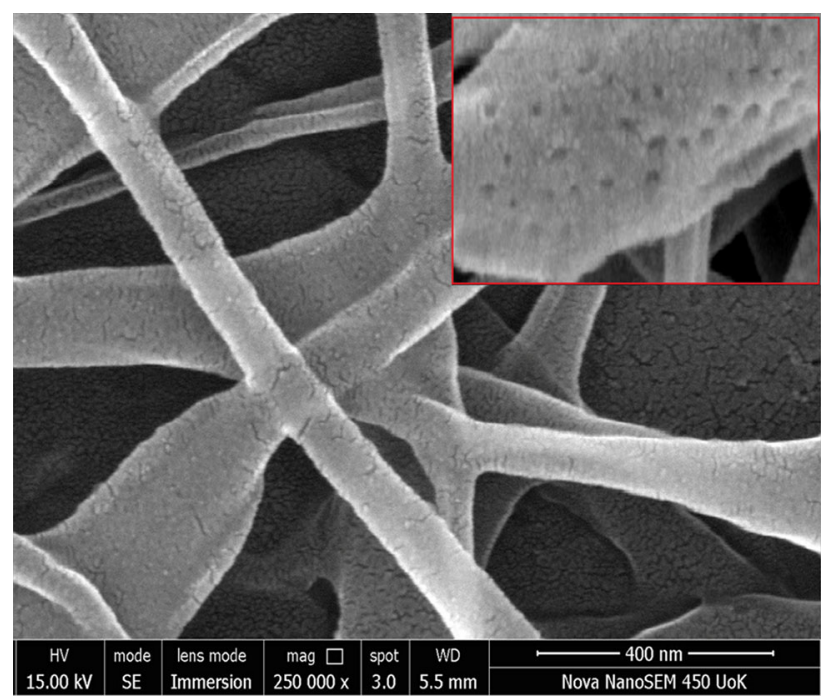

Figure 8. FESEM image of pure PMMA nanofibres; inset shows the close up view of the porous single PMMA nanofibre.

incorporation of the complex particles into the host matrix. The result shows the non-uniform nature of the particles in its size and shape. As the fibre is ultra-fine in both diameter and thickness, some fibres are damaged in the preparatory steps for taking TEM which can be seen in the images.

The selected area electron diffraction (SAED) patterns of the PMMA electrospun nanofibres embedded with samarium and neodymium $\beta$-diketonate complexes are shown in figure 10a and $\mathrm{b}$, respectively. This shows diffused rings formed by bright spots which indicated the polycrystalline nature of the complexes. Thus TEM analysis is evidence for the formation of complexes into the PMMA nanofibres.

\subsection{EDX analysis}

The EDX of PMMA electrospun nanofibres embedded with samarium and neodymium $\beta$-diketonate complexes are shown in figure 11a and $\mathrm{b}$. The corresponding information about the abundance of each element is shown in table $3 \mathrm{a}$ and $\mathrm{b}$.

The results obtained from EDX analysis show the successful incorporation of the complexes into the polymer matrix as the polymer contains 2.12 and $1.21 \%$ of the samarium and neodymium, respectively which again supports the results of SEM and TEM.

\subsection{PL studies}

The PL spectra of the pure PMMA, samarium and neodymium $\beta$-diketonate complexes and PMMA nanofibres embedded with samarium and neodymium $\beta$-diketonate complexes excited at their respective highest occupied molecular orbitallowest unoccupied molecular orbital gap energy are shown in figure $12 \mathrm{a}-\mathrm{d}$. The excitation wavelength for each sample is determined based on the maximum absorption wavelength obtained in UV-visible absorption analysis.

PMMA is subjected to different excitation wavelengths of $250,300,350$ and $400 \mathrm{~nm}$ and it was observed that a broad peak is obtained in the range of $370-450 \mathrm{~nm}$ in the visible region as shown in figure 12a. The PMMA nanofibres show the maximum intensity with $300 \mathrm{cps}$ at an excitation wavelength of $250 \mathrm{~nm}$. The samarium $\beta$-diketonate complex is subjected to photoluminescent studies at different excitation wavelengths of 320, 400 and $420 \mathrm{~nm}$ and the result is shown in figure 12b. The peak observed at $480 \mathrm{~nm}$ in the visible region indicates the band edge emission which is clear from the UV-visible absorption spectra of the present samples. The two peaks at 595 and $645 \mathrm{~nm}$ correspond to the characteristic
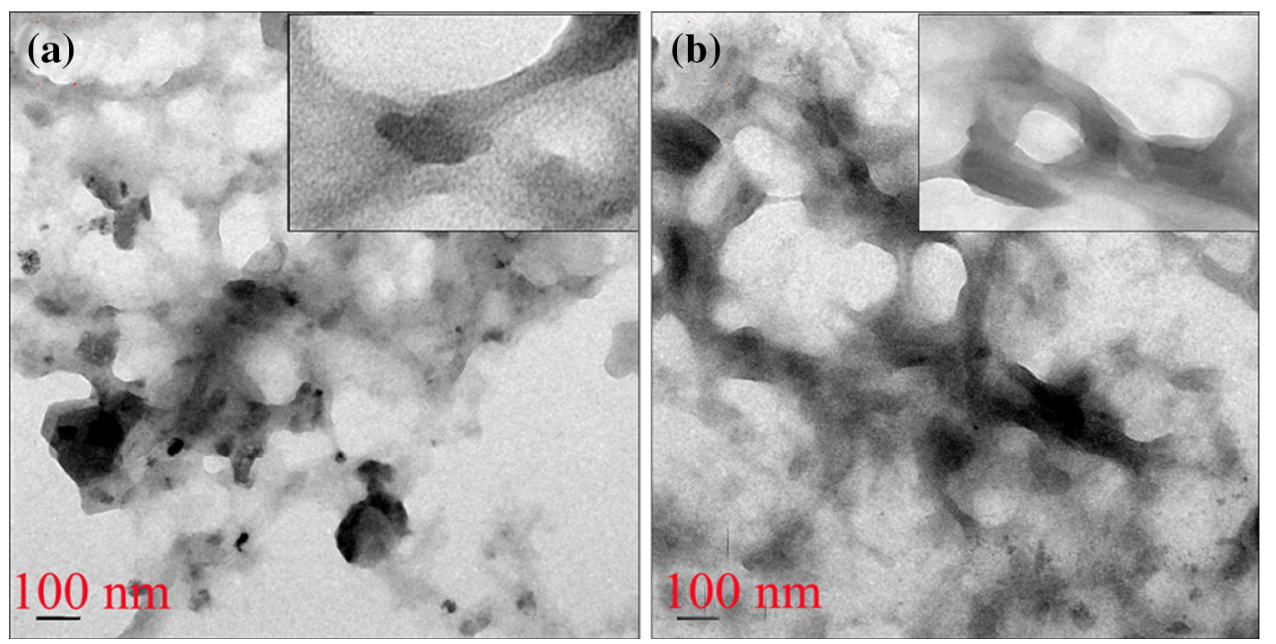

Figure 9. TEM images: (a) PMMA electrospun nanofibres embedded with the samarium $\beta$ diketonate complex and (b) PMMA electrospun nanofibres embedded with the neodymium $\beta$ diketonate complex. 

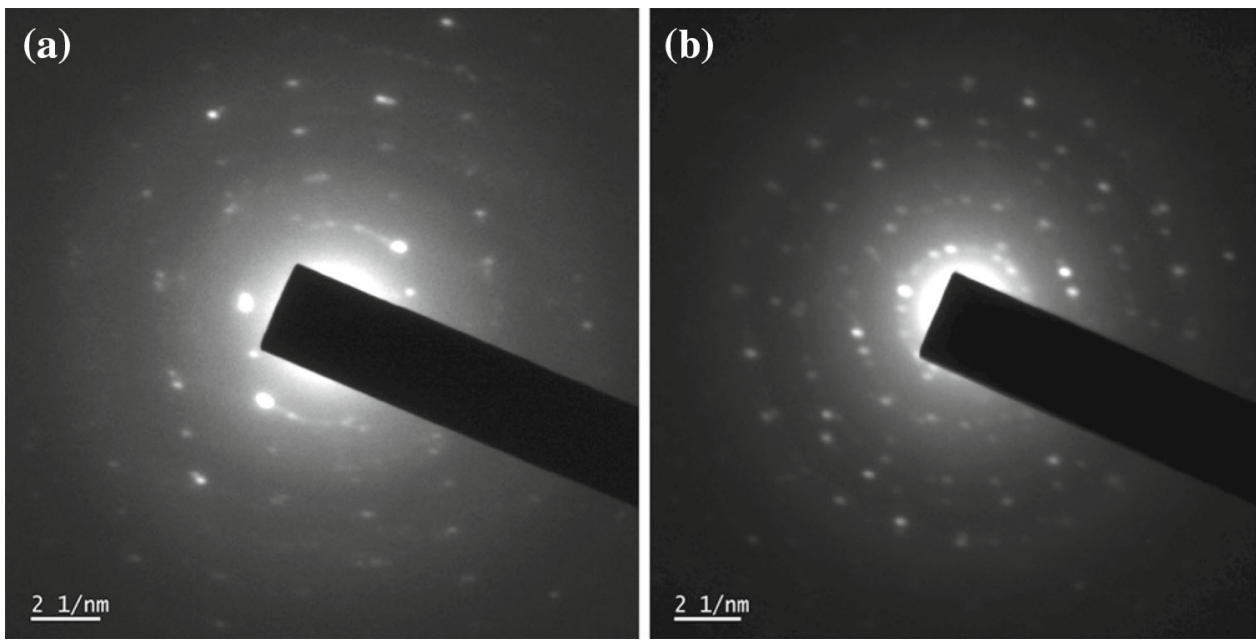

Figure 10. SAED images: (a) PMMA electrospun nanofibres embedded with the samarium $\beta$-diketonate complex and (b) PMMA electrospun nanofibres embedded with the neodymium $\beta$ diketonate complex.
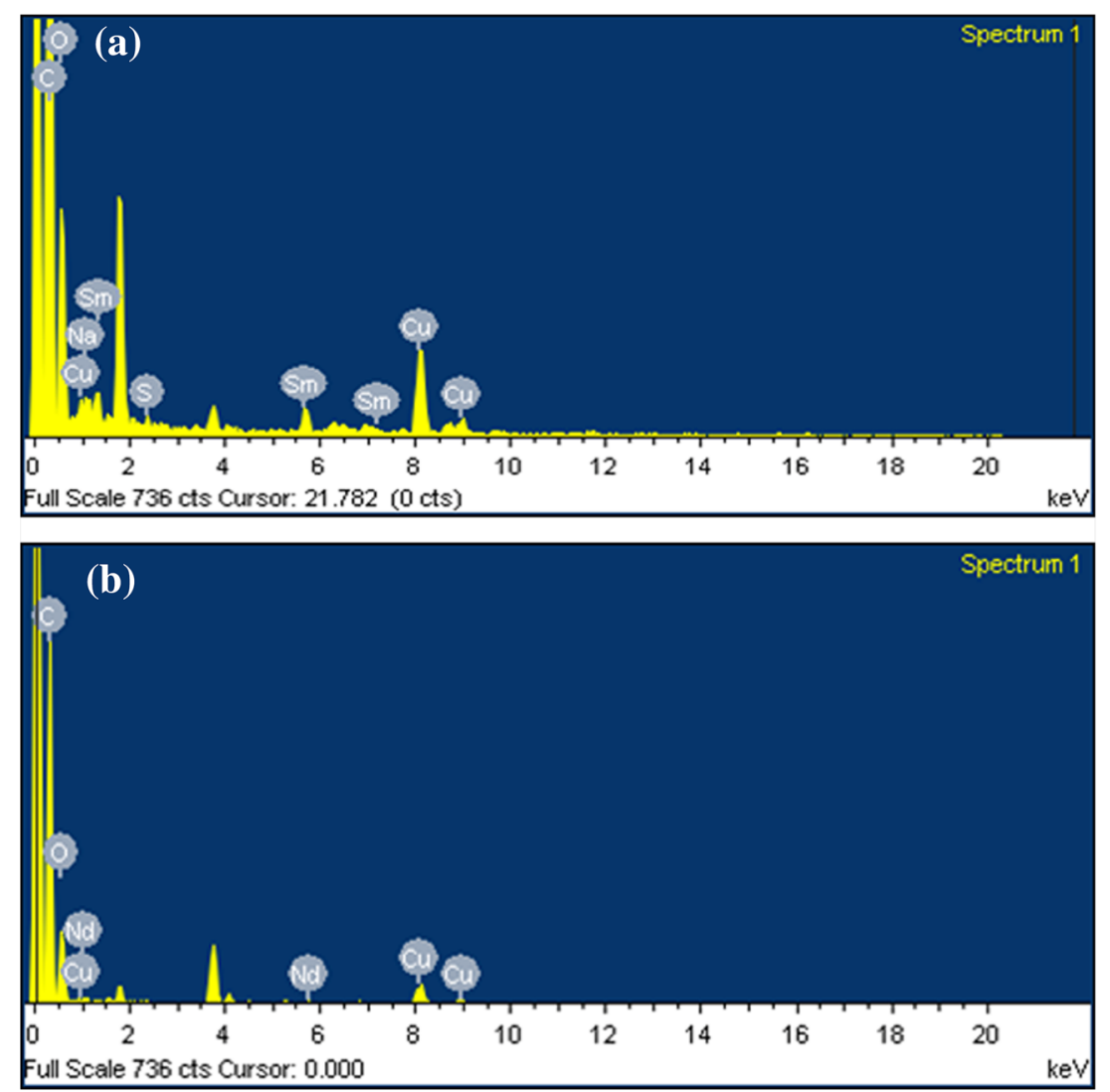

Figure 11. EDX spectra: (a) PMMA electrospun nanofibres embedded with the samarium $\beta$-diketonate complex and (b) PMMA electrospun nanofibres embedded with the neodymium $\beta$-diketonate complex. 
Table 3. Percentage abundances of various elements obtained from EDX.

Element $\quad$ Weight $(\%) \quad$ Atomic $(\%)$

(a) In the PMMA electrospun nanofibres embedded with samarium $\beta$-diketonate complexes

$\begin{array}{lrr}\text { C K } & 90.90 & 94.50 \\ \text { O K } & 6.59 & 5.14 \\ \text { Na K } & 0.19 & 0.10 \\ \text { S K } & 0.21 & 0.08 \\ \text { Sm L } & 2.12 & 0.18\end{array}$

(b) In the PMMA electrospun nanofibres embedded with neodymium $\beta$-diketonate complexes

$\begin{array}{lrr}\mathrm{C} \mathrm{K} & 78.51 & 87.03 \\ \mathrm{O} \mathrm{K} & 13.50 & 11.24 \\ \mathrm{Na} \mathrm{K} & 0.54 & 0.31 \\ \mathrm{Cu} \mathrm{K} & 6.24 & 1.31 \\ \mathrm{Nd} \mathrm{L} & 1.21 & 0.11\end{array}$

emissions from ${ }^{4} \mathrm{G}_{5 / 2}$ to ${ }^{6} \mathrm{H}_{7 / 2}$ and to ${ }^{6} \mathrm{H}_{9 / 2}$ of interstitial $\mathrm{Sm}^{3+}$ ions present in the complex respectively [26].

The PL spectra of the pure neodymium $\beta$-diketonate complex at excitation wavelengths of 300, 400, 500 and $520 \mathrm{~nm}$ are shown in figure 12c. The peak observed at $430 \mathrm{~nm}$ is assigned as band edge emission. The broad peak observed in the range of $440-470 \mathrm{~nm}$ corresponds to the main transitions from ${ }^{4} \mathrm{~F}_{3 / 2}$ to ${ }^{5} \mathrm{I}_{9 / 2}$ of interstitial $\mathrm{Nd}^{3+}$ ions present in the complex $[27,28]$. The blue shift occurring in the PL emission of the $\mathrm{Nd}$ complex from the near-infrared region to visible region is attributed to the presence of diketonate ligands in the prepared complex. Other peaks present in the photoluminescent spectrum of $\mathrm{Sm}$ and $\mathrm{Nd}$ complexes are due to emission from intermediate energy levels, donor-acceptor pair transitions, oxygen vacancies and interstitial ions present in the prepared complexes. No significant shift is observed in the photoluminescent results of the samples when subjected to different excitation wavelengths as shown in this figure. When the samarium and neodymium complexes are incorporated into the PMMA nanofibres, a broad PL emission is observed in the visible region as shown in figure $12 \mathrm{~d}$. The emission is similar to the emission of PMMA which proves the successful incorporation of the complexes into the PMMA fibre. Complexes incorporated PMMA fibres show much enhancement in intensity as evidenced from figure 12 .

In the present work, a comparative PL study is employed between the pristine PMMA and PMMA nanofibres incorporated with lanthanide complexes for determining the

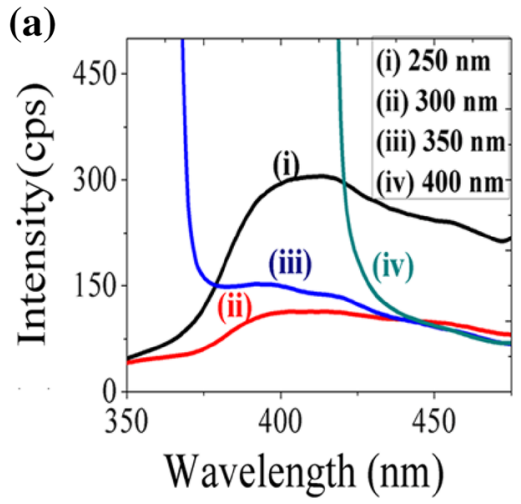

(b)

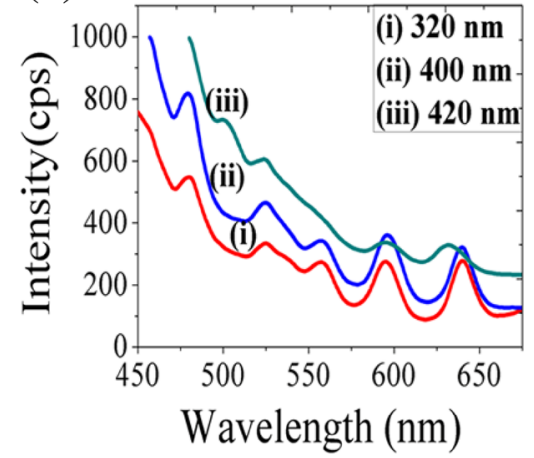

(c)

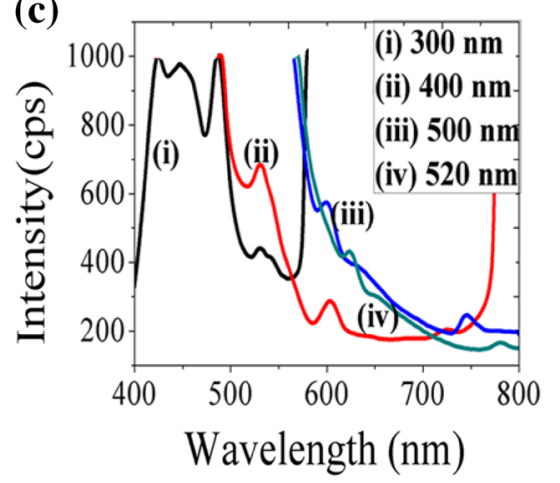

(d)

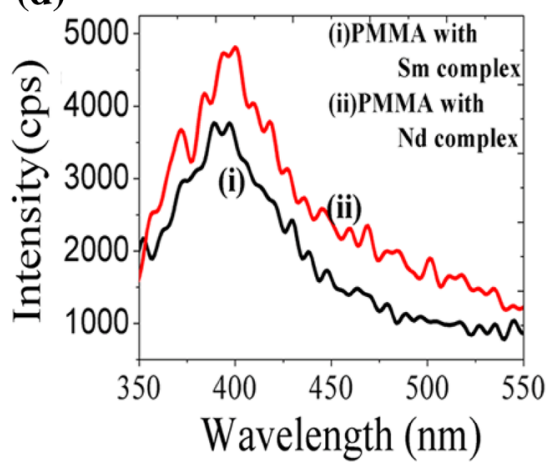

Figure 12. PL spectra: (a) pure PMMA, (b) Sm complex, (c) Nd complex and (d) (i) PMMA incorporated with the Sm complex and (ii) PMMA incorporated with the Nd complex. 
ability of the PL emission properties of the prepared samples. The PL emission intensity of the pure PMMA, pure samarium $\beta$-diketonate complex and complex-incorporated PMMA is 300,800 and $3800 \mathrm{cps}$, respectively as shown in figure $12 \mathrm{a}$, $\mathrm{b}$ and $\mathrm{d}$. The intensity of PMMA nanofibres incorporated with the samarium diketonate complex is about thirteen times higher than that of pristine PMMA nanofibres. Figure 12a, c and d shows that PL emission intensity of pure PMMA is 300 cps, the pure neodymium $\beta$-diketonate complex shows the maximum intensity at $1000 \mathrm{cps}$ whereas PMMA incorporated with the neodymium diketonate complex shows the maximum intensity at $4800 \mathrm{cps}$ which is sixteen times higher than the intensities of pure PMMA nanofibres. Hence, it could be indicated that the intensity of nanofibres incorporated with the lanthanide $\beta$-diketonate complex shows much higher intensity than that of pure PMMA nanofibres. The enhanced intensity behaviour can be attributed to the combined characteristics of transparent PMMA, luminescent lanthanides and fluorinated ligands present in the samarium and neodymium $\beta$-diketonate complexes incorporated PMMA nanofibre sample. Therefore, PMMA nanofibres incorporated with samarium and neodymium diketonate complexes are considered as suitable materials for modern display device applications such as lighting, organic LEDs and curved displays.

\section{Conclusion}

In summary, the PMMA nanofibres with diameter between 60-150 nm with $109 \mathrm{~nm}$ as the most distributed one are prepared through electrospinning. Sm and $\mathrm{Nd} \beta$-diketonate complexes are prepared using TTA ligand by precipitation method. The lanthanide complexes are found to be amorphous in nature and have a non-uniform and unpredicted morphology. The structural and molecular analysis shows the presence of some lanthanide oxides in the complex samples. The 'enol' form of the prepared lanthanide complex is proved using FTIR analysis. The successful incorporation of complexes into the PMMA nanofibre is well established by SEM, FESEM, TEM and FTIR analyses. The visible light absorption and reemission of the prepared samples are carried out by UV-visible absorption and PL analyses. The PL emission intensity of the lanthanide complexes incorporated PMMA nanofibre sample is much higher than that of the pure PMMA nanofibre due to the combined characteristics of luminescent lanthanide complexes and transparent PMMA. The present analysis proved that PMMA could act as the best host matrix not only to pure lanthanides or lanthanide oxides but also to lanthanide complexes with supreme optical properties. Hence, the PMMA polymer supported lanthanides have varieties of applications such as display devices, lighting devices and organic LEDs for curved display devices.

\section{Acknowledgements}

The authors thank UGC for financial assistance, KSCSTE for providing fund for the electrospinning machine and MATCH! 2 software developers for providing online facilities for comparing XRD patterns.

\section{References}

[1] Huang Z M, Zhang Y Z, Kotaki M and Ramakrishna S 2003 Compos. Sci. Technol. 632223

[2] Bhardwaj N and Kundu S C 2010 Biotechnol. Adv. 28325

[3] Frenot A and Chronakis I S 2003 Curr. Opin. Colloid Interface Sci. 864

[4] Lee C H, Chiang C L and Liu S J 2013 Sep. Purif. Technol. 118 737

[5] Li HF, Li G M, Chen P, Sun W B and Yan P F 2012 Spectrochim. Acta A 97197

[6] Lenaerts P, Driesen K, Deun R V and Binnemans K 2005 Chem. Mater. 172148

[7] Basak D, Karan S and Biswanath M 2006 Chem. Phys. Lett. 420115

[8] Chahar M, Ali V and Kumar S 2012 Int. J. Sci. Res. Publ. 21

[9] Binnemans K 2005 in Handbook on the physics and chemistry of rare earths $\mathrm{K}$ A Gschneidner, J C G Bünzli and V K Pecharsky (eds) (Leuven, Belgium: Elsevier) p 107

[10] Ali U, Karima K J A and Buang N A 2015 Polym. Rev. 55678

[11] Vincent T, Mukhopadhyay M and Wattal P K 2009 J. Supercrit. Fluids $\mathbf{4 8} 230$

[12] Otway D J and Rees W S 2000 Coord. Chem. Rev. 210279

[13] Dong H, Strawhecker K E, Snyder J F, Orlicki J A, Reiner R S and Rudie A W 2012 Carbohydr. Polym. 872488

[14] Li W, Yan P, Hou G, Li H and Li G 2013 RSC Adv. 318173

[15] Li M, Zhang Z, Cao T, Sun Y and Liang P 2012 Mater. Res. Bull. 47321

[16] Henry A C, Tutt T J, Galloway M, Davidson Y Y, McWhorter C S, Soper S A et al 2000 Anal. Chem. 725331

[17] Adati R D, Pavinatto F J, Monteiro J H S K, Davolos M R, Jafelicci M and Oliveira O N 2012 New J. Chem. 361978

[18] Ghosh D and Luwang M N 2015 RSC Adv. 547131

[19] Amali Roselin A, Anandhan N, Ravi G, Mummoorthi M and Marimuthu T 2014 Int. J. ChemTech Res. 65315

[20] El-Ansary A L and Abdel-Kader N S 2012 Int. J. Inorg. Chem. 20121

[21] Venkatesan N, Kamaraj P, Devikala S and Arthanareeswari M 2015 Rasāyan J. Chem. 8321

[22] Yu C, Zhang Z, Liu L, Feng W, Lü X, Wong W et al 2014 Inorg. Chem. Commun. 4930

[23] Hodgson G K, Impellizzeri S, Hallett-Tapley G L and Scaiano J C 2014 RSC Adv. 11

[24] Dong X and Hong G 2005 J. Mater. Sci. Technol. 21555

[25] Binnemans K 2009 Chem. Rev. 1094283

[26] Deng Z, Bai F, Xing Y, Xing N and Xu L 2013 Open J. Inorg. Chem. 376

[27] Andreiadis E S 2009 Chemical sciences (Grenoble I: Universite Joseph-Fourier) $\mathrm{p} 1$

[28] Sun L N, Yu J, Zhang H, Meng Q, Ma E, Peng C et al 2007 Microporous Mesoporous Mater. 98156 